\title{
Growth studies of various strains of $T$. vaginalis and possible improvements in the laboratory diagnosis of trichomoniasis
}

\author{
P. J. COX* AND C. S. NICOL \\ St. Thomas's Hospital, London
}

Trichomoniasis may be diagnosed by a direct smear examination and by culture of the organism. Cultures are usually examined after $24 \mathrm{hrs}$ ' incubation and thereafter daily up to 7 days; this technique is known to detect some infections in which direct smears have been found to be negative. It was felt that some improvements could be made in the culture technique used for diagnosis and an investigation was therefore made of the growth of different strains of $T$. vaginalis in various media. The chief aim of the study was to find the most suitable medium which would support the growth of the smallest inoculum of organisms in the shortest period of time. It was also hoped to standardize certain aspects of the routine laboratory diagnosis.

\section{Material and methods}

\section{CULTURE MEDIA}

In order to select a medium suitable for routine use, four different types of Trichomonas media were employed. The formulae of the media were as follows:

Stenton's medium (Stenton, 1957)

Ascorbic acid $1 \mathrm{~g}$.

L-cysteine hydrochloride $0.6 \mathrm{~g}$.

Dehydrated liver infusion (Oxoid) $0.25 \mathrm{~g}$.

Glucose $2 \cdot 5 \mathrm{~g}$.

Hartley's digest broth $460 \mathrm{ml}$.

†Calf serum 8 per cent. added before use $\mathrm{pH}$ adjusted to 6.0 Stored at $4^{\circ} \mathrm{C}$.

Oxoid Trichomonas medium No. 2 ( $\mathrm{R}$ 27)

The medium was obtained from the manufacturers ready to use.

Liver infusion $18 \mathrm{~g}$.

Hartley's digest broth $1,000 \mathrm{ml}$.

Horse serum $250 \mathrm{ml}$.

Calcium pantothenate, 0.5 per cent. $\mathrm{w} / \mathrm{v} 1 \mathrm{ml}$.

Dextrose $20 \mathrm{~g}$.

Chloramphenicol $0 \cdot 125 \mathrm{~g}$. pH $6 \cdot 2$ (approx.) Stored at $4^{\circ} \mathrm{C}$.

Feinberg-Whittington medium (Feinberg and Whittington, 1957)

The medium was supplied ready for use by Southern Group Laboratories.

Sodium chloride $6.5 \mathrm{~g}$.

Dextrose $5 \mathrm{~g}$.

Liver extract $25 \mathrm{~g}$.

Distilled water $1,000 \mathrm{ml}$.

Horse serum (inactivated) $80 \mathrm{ml}$.

Streptomycin 500,000 u.

Penicillin 1,000,000 u.

pH 6.2 Stored at $4^{\circ} \mathrm{C}$.

Modified Bushby's medium (Squires and McFadzean, 1962)

Tryptone soya broth $30 \mathrm{~g}$.

Dextrose $20 \mathrm{~g}$.

Liver infusion (Oxoid L 25) $18 \mathrm{~g}$.

Calcium pantothenate $(0.5$ per cent. solution) $1 \mathrm{ml}$.

Distilled water $1,000 \mathrm{ml}$.

${ }^{\star}$ Calf serum 20 per cent. added before use $\mathrm{pH} 6.0$ Stored at room temperature

Immediately before use chloramphenicol was added to all the above media, with the exception of Oxoid No. 2, at a final concentration of $1 \mathrm{mg} . / \mathrm{ml}$.

METHODS

(a) Growth of various strains of $\mathrm{T}$. vaginalis in modified Bushby's medium

$4.8 \mathrm{ml}$. volumes of modified Bushby's medium were pipetted aseptically into bijou bottles.

Three strains of $T$. vaginalis were employed. These were a May and Baker Reference strain (F 1295), which had been maintained for $3 \frac{1}{2}$ yrs in the laboratory, a strain recently isolated from a male patient, and a strain recently isolated from a female patient. All of these strains were maintained by sub-culturing into fresh media every $48 \mathrm{hrs}$.

The numbers of organisms per ml. in 24-hr cultures of each of the above strains were determined using a Burker haemocytometer chamber. The strains were then diluted to give similar concentrations and $0.2 \mathrm{ml}$. aliquots of each were then introduced into the medium, a duplicate series being set up for each strain.

*Activated calf serum (B.W. No. 2) substituted for horse serum 
After incubation for 24,48 , and $72 \mathrm{hrs}$ at $37^{\circ} \mathrm{C}$., the bottles were rocked mechanically for $2 \mathrm{~min}$. to break up any clumps of organisms, and the numbers of organisms per $\mathrm{ml}$. were again determined. The mean of the number of organisms per $\mathrm{ml}$. in the duplicate series was taken for each strain.

(b) Growth rate of one strain of $\mathrm{T}$. vaginalis in various media The following media were used: Modified Bushby's, Feinberg-Whittington, Oxoid No. 2, and Stenton's. All were brought to room temperature before inoculation.

The recently isolated strain from a female patient was used in this experiment and was inoculated into the media as described in (a) above. The number of organisms per ml. was determined after 24,48 , and $72 \mathrm{hrs}$ ' incubation at $37^{\circ} \mathrm{C}$.

(c) Influence of age of modified Bushby's medium on growth rate of $\mathrm{T}$. vaginalis

Three batches of modified Bushby's medium of different ages, were investigated-5 mths, $4 \mathrm{mths}$, and 1 week. These had all been stored at room temperature. Fresh serum was added immediately before starting the experiment.

The media were inoculated as described in (a) above and the number of organisms per $\mathrm{ml}$. was determined after 24 and $48 \mathrm{hrs}$ ' incubation at $37^{\circ} \mathrm{C}$.

(d) Determination of the minimum inoculum to obtain growth $0.5 \mathrm{ml}$. of the $M$ and $B$ strain of $T$. vaginalis containing $10^{6}$ organisms was inoculated into $4.5 \mathrm{ml}$. of modified Bushby's medium. Serial 10-fold dilutions were then made to obtain cultures containing $10^{5}, 10^{4}, 10^{3}, 10^{2}$, and $10^{1}$ organisms respectively.

After 24, 48, 72, 96, and 148 hrs' incubation, samples were taken from the sediment in the culture bottles, using a Pasteur pipette, and were examined microscopically for 3 minutes. The presence or absence of organisms was noted.

(e) Determination of the optimum incubation period Two media, Feinberg-Whittington and modified Bushby's were employed for this experiment. Specimens from forty female patients were inoculated into each of the media using serum-coated swabs. The cultures were examined daily for 5 days in order to determine the optimum incubation time for detecting the organisms.

( $f$ ) Comparison of two media with direct smear examination for the isolation of $T$. vaginalis

Specimens from 73 female patients were examined by direct smear, and each was then inoculated into FeinbergWhittington medium and modified Bushby's medium, as in $(e)$ above. These cultures were incubated at $37^{\circ} \mathrm{C}$. and examined microscopically on the following day (the incubation period ranged from 16 to $24 \mathrm{hrs}$ ).

(g) Determination of optimum duration of examination A series of cultures which had been found to be positive by routine examination was re-examined for 2,3 , and 5 min. and the number of positive cultures recorded for each period of examination.

Throughout the above experiments cultures were regarded as being positive only when the organisms were seen to be motile.
Results

(a) Growth of various strains of T. vaginalis in modified Bushby's medium (Fig. 1)
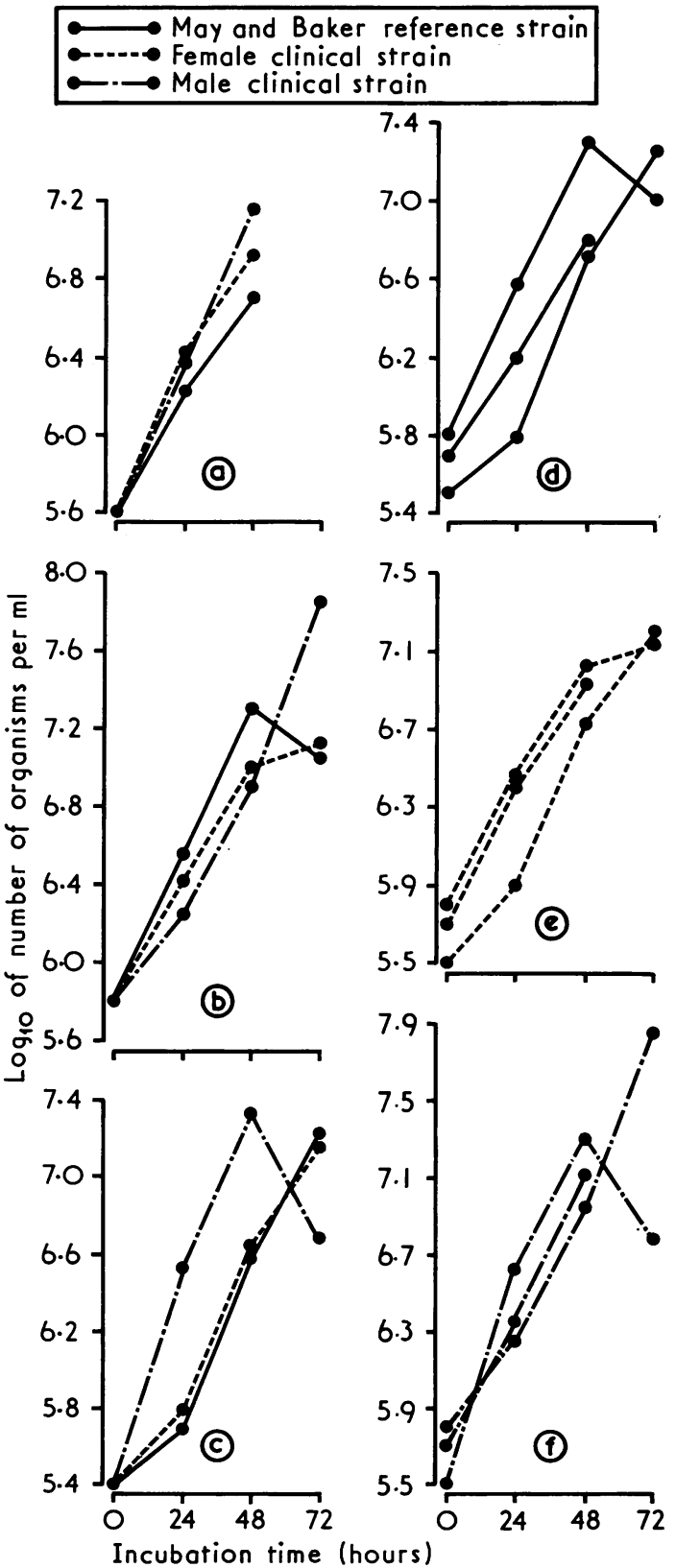

FIG. 1 Each of the graphs $(A, B, C)$ represents the growth of various strains in single experiments Each of the graphs $(D, E, F)$ represents the growth of one strain in three different experiments 
The comparative rate of growth of the three strains varied from experiment to experiment as did the rate of growth of each strain in different experiments

(b) Growth rate of one strain of $\mathrm{T}$. vaginalis in various media

The results of a single set of observations, typical of a series, are shown in Fig. 2.

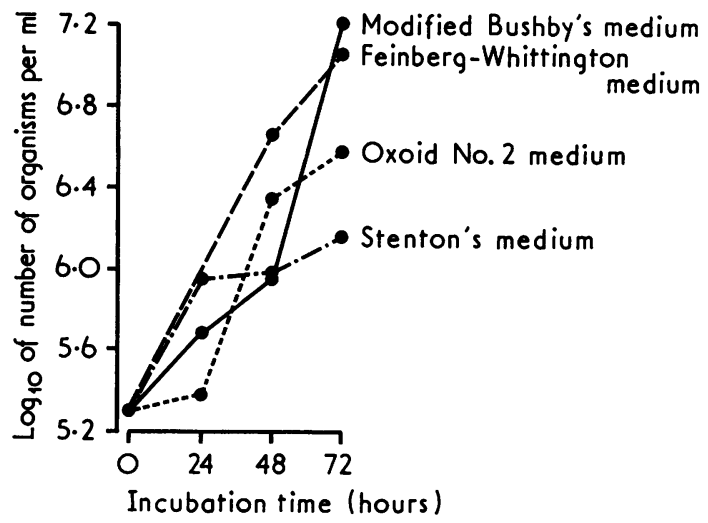

FIG. 2 Growth rate of one strain of $\mathrm{T}$. vaginalis in various media

The two media which consistently gave the best growth were modified Bushby's and FeinbergWhittington.

(c) Influence of age of modified Bushby's medium on growth rate of $\mathrm{T}$. vaginalis

Fig. 3 shows that all batches of medium supported the growth of the organisms adequately. However, at $48 \mathrm{hrs}$, the highest number of viable organisms was observed in the freshest batch of medium.

(d) Determination of minimum inoculum required to obtain growth

Table I shows the time of detection of positive growth after different sizes of inoculum. Organisms were detected after incubation for $148 \mathrm{hrs}$, after an inoculum of $10^{2}$. No growth was detected after an inoculum of $10^{1}$ organisms after incubation for 148 hrs. An inoculum of $10^{5}$ organisms gave visible growth after $24 \mathrm{hrs}$ ' incubation.

TABLE I Determination of minimum inoculation for growth

\begin{tabular}{ll}
\hline Inoculum & Time at which organisms were detected (hrs) \\
\cline { 1 - 1 } & 24 \\
$10^{5}$ & 48 \\
$10^{3}$ & 72 \\
$10^{2}$ & Not detected up to 148 \\
$10^{1}$ & \\
\hline
\end{tabular}

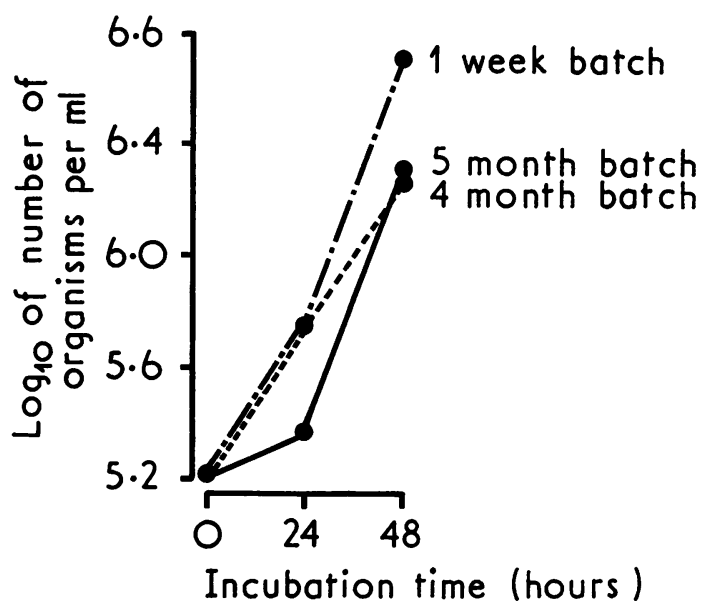

FIG. 3 Influence of age of modified Bushby's medium on growth rate of $T$. vaginalis

(e) Determination of optimum incubation period

The total number of positive cultures obtained from the forty samples was 23 ; nineteen ( 83 per cent.) of these positives were detected at $24 \mathrm{hrs}$, two at $48 \mathrm{hrs,}$ one at $72 \mathrm{hrs}$, and one at $120 \mathrm{hrs}$ in modified Bushby's medium. A 24-hr examination of the cultures in Feinberg-Whittington yielded 21 (91 per cent.) of the positives, but no further positives were detected up to $120 \mathrm{hrs}$.

(f) Comparison of two media with direct smear examination for the isolation of $\mathrm{T}$. vaginalis

Positive cultures, in both media, confirmed the diagnosis in the eight out of 73 patients found to be positive by direct smear; Table II shows that five extra positive diagnoses were made using either modified Bushby's or Feinberg-Whittington as the culture medium.

TABLE II Comparison of two media for the isolation of $\mathrm{T}$. vaginalis

\begin{tabular}{|c|c|c|c|}
\hline \multirow{2}{*}{ Method of diagnosis } & \multirow{2}{*}{$\begin{array}{l}\text { Direct } \\
\text { smear } \\
\text { examination }\end{array}$} & \multicolumn{2}{|l|}{ Culture } \\
\hline & & Bushby & Feinberg \\
\hline No. diagnosed as positive & 8 & 13 & 13 \\
\hline No. of samples observed & $\overline{73}$ & $\overline{73}$ & $\overline{73}$ \\
\hline
\end{tabular}

(g) Determination of optimum duration of examination A 2-minute search was sufficient to detect 100 per cent. of the positives, 92 per cent. of them being detected within the first 30 seconds of the search. 


\section{Discussion}

There was little difference between the growth of a recently isolated strain of $T$. vaginalis and that of a laboratory reference strain; however, the growth of each individual strain was very variable from experiment to experiment.

All the media used supported the growth of organisms, but modified Bushby's and FeinbergWhittington gave the greatest growth over $72 \mathrm{hrs}$. The different levels of growth of $T$. vaginalis in batches of Bushby's medium of various ages indicate that the medium deteriorates on extended storage, but is still capable of supporting some growth.

An inoculum of $10^{2}$ organisms was required to obtain detectable growth by $148 \mathrm{hrs}$, and an inoculum of $10^{5}$ organisms gave growth at $24 \mathrm{hrs}$. From this it can be assumed that the 21 cultures recorded as positive at $24 \mathrm{hrs}$ (19 in modified Bushby's and 21 in Feinberg-Whittington) had been inoculated with at least $10^{5}$ organisms.

Each of the two culture media compared for the isolation of organisms gave an equivalent increase in the number of positives detected over those recorded by direct smears.

From this work it can be deduced that, if organisms are inoculated into either modified Bushby's or Feinberg-Whittington medium, incubated for $24 \mathrm{hrs}$ at $37^{\circ} \mathrm{C}$, and examined for $2 \mathrm{~min}$., the number of positive cases diagnosed may be expected to be considerably higher than the number diagnosed by direct smear examination.

\section{Summary}

(1) The growth rates of three different strains of Trichomonas vaginalis in modified Bushby's medium were compared and found to vary from experiment to experiment.

(2) The growth rates of one strain of $T$. vaginalis in four different media were compared. Modified Bushby's and Feinberg-Whittington were the most satisfactory media for supporting growth.

(3)The influence of the age of the modified Bushby's medium on the growth rate of $T$. vaginalis was studied. 5-month-old media supported growth but to a lesser degree than did 1-week-old media.

(4) Methods of improving the laboratory diagnosis of
$T$. vaginalis in clinical cultures were investigated. If organisms are inoculated into either modified Bushby's medium or Feinberg-Whittington medium, incubated for $24 \mathrm{hrs}$ at $37^{\circ} \mathrm{C}$, and examined for $2 \mathrm{~min}$., the number of positive cases diagnosed may be expected to be considerably higher than the number diagnosed by direct smear examination.

We wish to acknowledge the help of the staff of the Lydia Department, St. Thomas's Hospital, and a grant from the St. Thomas's Hospital Research Fund.

Our thanks are also due to Dr. J. A. McFadzean for much helpful advice and encouragement in the course of this work.

\section{References}

FeinberG, J. G., and Whittington, M. J. (1957) $\mathcal{f}$. clin. Path., 10, 327

SQuires, S., and McFadzeAn, J. A. (1962) Brit. F. vener. Dis., 38, 218

Stenton, P. (1957) f. med. Lab. Technol., 14, 228

Études de la pousse de souches variées de $T$. vaginalis et améliorations possibles du diagnostic de laboratoire de la trichomonase

\section{SOMMAIRE}

(1) On a comparé les taux de croissance de souches différentes de $T$. vaginalis dans le milieu modifié de Bushby et on les a trouvés variables d'une expérience à l'autre.

(2) Les taux de croissance d'une souche de $T$. vaginalis furent comparées pour quatre milieux différents. Le milieu de Bushby modifié et celui de Feinberg-Whittington furent trouvés les plus satifaisants.

(3) On a étudié l'influence de l'âge du milieu de Bushby modifié sur le taux de croissance de $T$. vaginalis. Des milieux vieux de 5 mois permettaient la pousse mais à un moindre degré que des milieux datant d'une semaine.

(4) Des méthodes en vue d'améliorer le diagnostic de laboratoire du $T$. vaginalis par culture en pratique clinique ont fait l'objet de recherches. Si les organismes sont inoculé soit dans le milieu de Bushby modifié, soit dans le milieu Feinberg-Whittington, mis à l'incubation pour 24 heures à $37 \mathrm{C}$. et examinés pendant 2 minutes, on peut s'attendre à ce que le nombre des cas positifs diagnostiqués soit considérablement plus élevé que celui des cas diagnostiqués par l'examen direct de la sécrétion. 